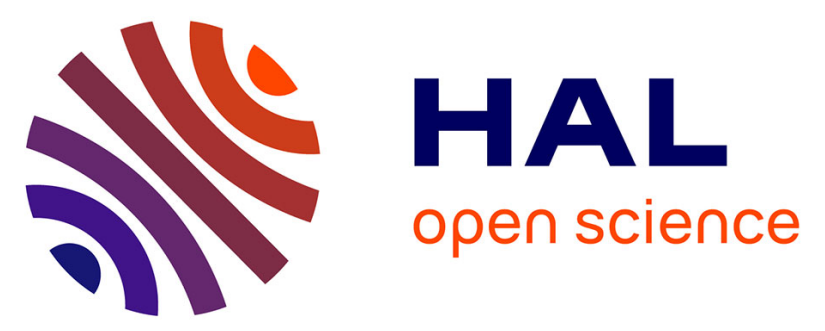

\title{
Efficacy of caspofungin and itraconazole as secondary antifungal prophylaxis: analysis of data from a multinational case registry
}

Jörg J. Vehreschild, Michal Sieniawski, Stefan Reuter, Dorothee Arenz, Dietmar Reichert, Johan Maertens, Angelika Böhme, Gerda Silling, Rodrigo

Martino, Georg Maschmeyer, et al.

\section{To cite this version:}

Jörg J. Vehreschild, Michal Sieniawski, Stefan Reuter, Dorothee Arenz, Dietmar Reichert, et al.. Efficacy of caspofungin and itraconazole as secondary antifungal prophylaxis: analysis of data from a multinational case registry. International Journal of Antimicrobial Agents, 2009, 34 (5), pp.446. 10.1016/j.ijantimicag.2009.06.025 . hal-00556353

\section{HAL Id: hal-00556353 https://hal.science/hal-00556353}

Submitted on 16 Jan 2011

HAL is a multi-disciplinary open access archive for the deposit and dissemination of scientific research documents, whether they are published or not. The documents may come from teaching and research institutions in France or abroad, or from public or private research centers.
L'archive ouverte pluridisciplinaire HAL, est destinée au dépôt et à la diffusion de documents scientifiques de niveau recherche, publiés ou non, émanant des établissements d'enseignement et de recherche français ou étrangers, des laboratoires publics ou privés. 


\section{Accepted Manuscript}

Title: Efficacy of caspofungin and itraconazole as secondary antifungal prophylaxis: analysis of data from a multinational case registry

Authors: Jörg J. Vehreschild, Michal Sieniawski, Stefan Reuter, Dorothee Arenz, Dietmar Reichert, Johan Maertens, Angelika Böhme, Gerda Silling, Rodrigo Martino, Georg Maschmeyer, Maria J.G.T. Rüping, Andrew J. Ullmann, Oliver A. Cornely

PII: $\quad$ S0924-8579(09)00347-1

DOI: doi:10.1016/j.ijantimicag.2009.06.025

Reference: ANTAGE 3082

To appear in: International Journal of Antimicrobial Agents

Received date: $\quad$ 6-3-2009

Revised date: $\quad$ 12-6-2009

Accepted date: $\quad$ 15-6-2009

Please cite this article as: Vehreschild JJ, Sieniawski M, Reuter S, Arenz D, Reichert D, Maertens J, Böhme A, Silling G, Martino R, Maschmeyer G, Rüping MJGT, Ullmann AJ, Cornely OA, Efficacy of caspofungin and itraconazole as secondary antifungal prophylaxis: analysis of data from a multinational case registry, International Journal of Antimicrobial Agents (2008), doi:10.1016/j.ijantimicag.2009.06.025

This is a PDF file of an unedited manuscript that has been accepted for publication. As a service to our customers we are providing this early version of the manuscript. The manuscript will undergo copyediting, typesetting, and review of the resulting proof before it is published in its final form. Please note that during the production process errors may be discovered which could affect the content, and all legal disclaimers that apply to the journal pertain. 


\section{Efficacy of caspofungin and itraconazole as secondary antifungal prophylaxis: analysis of data from a multinational case registry}

Jörg J. Vehreschild ${ }^{\mathrm{a}, 1}$, Michal Sieniawski ${ }^{\mathrm{a}, 1}$, Stefan Reuter ${ }^{\mathrm{b}}$, Dorothee Arenz ${ }^{\mathrm{a}, \mathrm{c}}$, Dietmar Reichert $^{d}$, Johan Maertens ${ }^{e}$, Angelika Böhme ${ }^{f}$, Gerda Silling ${ }^{g}$, Rodrigo Martino h, Georg Maschmeyer ', Maria J.G.T. Rüping ${ }^{\text {a }}$, Andrew J. Ullmann ${ }^{\text {j, }}$ Oliver A. Cornely ${ }^{\mathrm{a}, \mathrm{c}, *}$

a Klinik I für Innere Medizin, Klinikum der Universität zu Köln, Cologne, Germany

${ }^{\mathrm{b}}$ Klinik für Gastroenterologie, Hepatologie und Infektiologie, Universitätsklinikum Düsseldorf, Düsseldorf, Germany

${ }^{c}$ Zentrum für Klinische Studien (ZKS Köln; BMBF 01KN0706), Klinikum der Universität zu Köln, Cologne, Germany

d Hämatologisch-Onkologische Gemeinschaftspraxis Dr Reichert/Dr Janssen, Westerstede, Germany

e Department of Hematology, University Hospital Gasthuisberg, Leuven, Belgium

f Onkologikum Frankfurt am Museumsufer, Frankfurt, Germany

${ }^{9}$ Medizinische Klinik A des Universitätsklinikums Münster, Münster, Germany

h Division of Clinical Hematology, Hospital de la Santa Creu i Sant Pau

Barcelona, Barcelona, Spain 
' Klinik für Hämatologie und Onkologie, Klinikum Ernst von Bergmann, Potsdam, Germany

j 3rd Medical Department, Johannes Gutenberg Universität Mainz, Mainz, Germany

\section{ARTICLE INFO}

Article history:

Received 6 March 2009

Accepted 15 June 2009

Keywords:

Antifungal prophylaxis

Stem cell transplantation

Aspergillosis

Itraconazole

Caspofungin

* Corresponding author. Present address: Klinikum der Universität zu Köln, Kerpener Str. 62, 50937 Köln, Germany. Tel.: +49 221478 6494; fax +49 221 4783611.

E-mail address: oliver.cornely@ctuc.de (O.A. Cornely).

${ }^{1}$ These authors contributed equally to this paper. 
Page 3 of 30 


\section{ABSTRACT}

Patients surviving invasive fungal disease (IFD) and needing further antineoplastic chemotherapy are at high risk of recurrent fungal infection. In the absence of randomised controlled trials in this area, secondary prophylactic regimens are diverse. From 448 patients registered with the Multinational Case Registry of Secondary Antifungal Prophylaxis, we performed an analysis of patients receiving caspofungin (CAS) or itraconazole (ITC). All patients had an underlying haematological malignancy and had been diagnosed with an episode of IFD earlier in their course of treatment. Data collected comprised demographics, underlying disease, first episode of IFD, antifungal prophylaxis, incidence and outcome of breakthrough IFD and survival. A total of 75 patients were evaluated, comprising 28 receiving CAS and 47 receiving ITC. Patients in the CAS group were more likely to have had progression of underlying disease $(32.1 \%$ vs. $8.5 \% ; P=0.028)$ as well as incomplete response of initial IFD at baseline $(85.7 \%$ vs. $57.4 \% ; P=0.005)$. Allogeneic stem cell transplantation was more prevalent in patients receiving CAS $(46.4 \%$ vs. $14.9 \% ; P=0.010)$. There was no difference in the occurrence of breakthrough IFD between both groups (32.1\% vs. $31.9 \%)$. Treatment outcomes for recurrent IFD and overall mortality did not differ between groups. Both ITC and CAS were equally effective in preventing second episodes of IFD. Patients with uncontrolled first IFD, uncontrolled underlying disease or those receiving stem cell transplantation were more likely to have received CAS prophylaxis. Despite antifungal prophylaxis, risk of breakthrough IFD was high in both groups. 


\section{Introduction}

Invasive fungal diseases (IFDs) remain a major cause of treatment-related morbidity and mortality in patients with haematological malignancy and neutropenia [1,2] and the incidence of IFD has actually been rising over the last decades [3]. This change is attributed to increased use of intensified chemotherapy protocols, allogeneic stem cell transplantation (SCT) and immunosuppressive treatments in elderly or co-morbid patients [4]. The most common IFDs in neutropenic patients are invasive pulmonary aspergillosis and invasive candidiasis, including candidaemia [5]. New antifungal agents, i.e. the echinocandins, newer triazoles and lipid formulations of amphotericin B (AMB), represent effective and well tolerated treatment options [6-8]. This may have encouraged clinicians to proceed with dose-intense chemotherapy even in patients having contracted IFD during previous cycles of treatment. However, these patients are at high risk of recurrent IFD, often with fatal outcome. The reported incidence rates of recurrent IFD range from $16 \%$ to $33 \%$ [9-11], and IFD-related mortality may be as high as $88 \%[10,12,13]$.

At present there are no standard procedures for secondary antifungal prophylaxis in these patients and treatment decisions are based mainly on results from firstline treatment trials. Antifungal agents reported to have been used for secondary prophylaxis include AMB formulations, flucytosine, itraconazole (ITC), fluconazole (FLC) and voriconazole (VRC) [14]. Two retrospective studies 
demonstrated an ca. $30 \%$ incidence of recurrent IFD in patients undergoing allogeneic SCT after a previous episode of IFD, despite secondary antifungal prophylaxis with AMB, ITC and/or FLC $[10,11]$.

ITC has frequently been used as secondary antifungal prophylaxis owing to its activity against clinically relevant fungal pathogens. However, ITC has a complex drug-drug interaction profile [15-19] and the tolerability of ITC is poor compared with FLC [19] secondary antifungal prophylaxis. Caspofungin (CAS) has a favourable tolerability profile and very few clinically relevant drug-drug interactions [20]. The purpose of this study was to compare ITC and CAS as secondary prophylaxis in patients with haematological malignancies and a history of proven or probable IFD who received subsequent chemotherapy associated with grade 4 neutropenia [21].

\section{Methods}

\subsection{Patient population}

From October 2001 to July 2004, data from 448 patients were prospectively collected and analysed in the Multinational Case Registry of Secondary Antifungal Prophylaxis, a project of the ID Working Party of the German Society for Hematology and Oncology. The study was non-interventional and treatment choice was at the physician's discretion. Inclusion criteria were: (i) history of proven or probable IFD during the most recent neutropenic episode; (ii) diagnosis 
of acute leukaemia or other haematological malignancy; (iii) secondary antifungal prophylaxis with ITC oral solution (dose $\geq 400 \mathrm{mg} /$ day) or intravenous CAS; and (iv) a current neutropenic episode of at least 3 days. Patients receiving both ITC and CAS were excluded. IFD was diagnosed according to the consensus criteria of the European Organisation for Research and Treatment of Cancer (EORTC) and the Mycoses Study Group (MSG) [22].

\subsection{Data collection}

A case report form was accessible through the Internet, allowing anonymised data entry and electronic transfer into a relational database. Information obtained included patient characteristics (age, gender and underlying malignancy), details regarding first IFD (including fungal species, site of infection, treatment regimens and outcome) and current neutropenic episode (including duration of neutropenia, antifungal regimen, risk factors for IFD, fungal breakthrough infections, treatment results of underlying malignancy, survival and cause of death if appropriate). In the case of breakthrough IFD, additional data were obtained on fungal species and organ involvement as well as treatment outcome. Plausibility controls were carried out for all data received and queries were issued when necessary for further clarification. Outcome was assessed at the end of neutropenia. No further follow-up was performed. 


\subsection{Diagnosis and response assessment}

Diagnosis assessment of first and breakthrough IFD according to the early draft of the EORTC/MSG criteria used in two major clinical trials $[7,23]$ was made by the investigator. Investigators agreed to use appropriate diagnostic methods as described in the EORTC/MSG criteria, including clinical examination, microbiological and histopathological tests, and imaging techniques. Complete response was defined as the disappearance of all clinical, microbiological and radiographic evidence of infection, and partial response was defined as a $>50 \%$ reduction in radiological infection signs. Stable disease was defined as stable signs of infection within a minimum of 4 weeks, and progressive was disease defined as increase of infection signs. Response was evaluated by the investigators.

The status of the underlying malignancy was evaluated according to World Health Organization criteria [24]. Complete remission was defined as the complete disappearance of disease for at least 4 weeks. Partial remission was defined as a $>50 \%$ reduction in the tumour lasting at least 4 weeks. Stable disease was defined as unchanged disease status for a minimum of 4 weeks, and progression as an increase of disease. 


\subsection{Variables}

Other variables included in the analysis were demographics and potential confounders, i.e. age, gender, type of transplant, isolation measures, site, treatment, response, evidence and pathogen of first IFD, site and evidence of breakthrough IFD, as well as mortality and attributable mortality, defined as death during uncontrolled IFD.

\subsection{Statistical analysis}

Demographics and disease characteristics were summarised using descriptive statistics. The $\chi^{2}$ test, Fisher's exact test and $t$-test test were used as appropriate with a confidence interval of $95 \%$ to investigate differences in proportions and means, respectively. No multivariate analysis was performed due to the relatively small number of patients. Statistical analysis was performed with SPSS Version 16.0.1 (SPSS Inc., Chicago, IL).

\subsection{Reporting}

Data analyses and reporting were performed with attention to the Strengthening the Reporting of Observational Studies in Epidemiology (STROBE) statement [25]. 


\section{Results}

Of 448 patients, 77 fulfilled the inclusion criteria, comprising 28 receiving CAS and 49 receiving ITC for secondary prophylaxis. Two patients from the ITC group were excluded because of incomplete data (unknown formulation of ITC and missing leukocyte counts). Some data for 5 patients from the CAS group and 22 patients from the ITC group were part of an earlier publication on risk factors for breakthrough infections [9]. Owing to the sample size, no formal matching of patients was performed. Patients in the ITC group were more likely to have controlled underlying disease at baseline and less frequently underwent SCT (Table 1). Prior IFD was more likely to be controlled when starting secondary prophylaxis in patients in the ITC group (Table 2).

Most patients in the CAS group (86\%) were administered a daily dose of $50 \mathrm{mg}$; two patients received $70 \mathrm{mg} /$ day and two others received a loading dose of 70 $\mathrm{mg}$ followed by $50 \mathrm{mg}$ maintenance dose. In the ITC group the majority of patients $(87 \%)$ received $400 \mathrm{mg} /$ day ITC, three patients $(6 \%)$ received 500 $\mathrm{mg} /$ day and three other patients (6\%) received $600 \mathrm{mg} /$ day. Therapeutic drug monitoring was carried out in $66 \%$ of patients in the ITC group. For most of these (68\%), the total target plasma level of ITC and its metabolite hydroxyitraconazole was $>500 \mu \mathrm{g} / \mathrm{L}$, followed by $>750 \mu \mathrm{g} / \mathrm{L}$ in one patient $(3 \%)$ and $>1000 \mu \mathrm{g} / \mathrm{L}$ in nine patients (29\%). 
Of note, a significantly greater number of patients from the CAS group compared with the ITC group had liver and/or spleen involvement during their first IFD (25\% vs. $0 \%$ liver and $14 \%$ vs. $0 \%$ spleen; Fisher's exact test, $P=0.001$ and $P=$ 0.017, respectively) (Table 2). Treatment of baseline IFD included conventional and lipid formulations of AMB, CAS, ITC, FLC, VRC and 5-flucytosine (Table 2). Three patients in each group underwent surgery as treatment of first IFD [not significant (N.S.)].

More patients in the CAS group than in the ITC group started with secondary antifungal prophylaxis when initiating chemotherapy (79\% and $36 \%)$. The strategy most frequently chosen for the other patients was to proceed continuously from treatment of first IFD to secondary prophylaxis (21\% and $36 \%)$. In all of these cases, the prophylactic regimen differed from the previous treatment regimen. The remainder began prophylaxis when the neutrophil count declined below $500 / \mu \mathrm{L}(0 \%$ and $19 \%)$, at occurrence of fever $(0 \%$ and $4 \%)$ or at discharge from hospital $(0 \%$ and $4 \%)$. Initiation of prophylaxis between both treatment groups differed significantly $\left(\chi^{2}\right.$ test, $\left.P<0.008\right)$.

Most patients in both groups stopped secondary antifungal prophylaxis at the end of neutropenia (39.3\% and $40.4 \%)$. More patients in the ITC group needed targeted antifungal therapy (7.1\% and $27 . \%)$. Other reasons for treatment discontinuation were toxicity $(0 \%$ and $4.3 \%)$, death $(10.7 \%$ and $2.1 \%)$, other reasons $(25.0 \%$ and $6.4 \%)$ or unknown $(7.1 \%$ and $2.1 \%)$. Prophylaxis was 
continued in $10.7 \%$ and $17.0 \%$. The reasons for discontinuing prophylaxis were significantly different between both groups (Fisher's exact test, $P<0.027$ ).

The incidence of breakthrough IFD under secondary prophylaxis was almost identical in both groups (32.1\% and 31.9\%) (Fig. 1). A trend towards fewer proven or probable breakthrough IFD in the ITC group was not significant $(29 \%$ and $17 \%)$. A high target plasma level of ITC of $>1000 \mu \mathrm{g} / \mathrm{L}$ did not offer protection from breakthrough infections (44.4\% possible, $11.1 \%$ probable, $11.1 \%$ proven breakthrough IFD). There was no significant difference in the incidence of proven, probable or possible breakthrough IFD between patients with continuous and non-continuous antifungal prophylaxis. Patients with uncontrolled first IFD were numerically more likely to experience recurrent IFD (55.6\%) than patients achieving at least a partial response of first IFD (28.8\%) (N.S.). One patient in each group had proven breakthrough infection due to Aspergillus fumigatus and one patient in the ITC group due to Fusarium oxysporum. The outcome of breakthrough IFD was similar in both groups (Table 3). The rate of breakthrough fungal infections was comparable when looking at the subgroup of patients with proven first IFD, with one patient in each group showing proven or probable breakthrough IFD (13.3\%).

Overall survival favoured the ITC group, but this trend was not significant $(75 \%$ and $89 \%$ ). Death was attributed to IFD in $3.6 \%$ and $4.3 \%$, i.e. one patient in the 
CAS group and two patients in the ITC group (Table 3). Mortality of probable or proven breakthrough IFD was $18.8 \%$.

\section{Discussion}

Our exploratory study involved 75 patients with a recent history of probable or proven IFD receiving secondary antifungal prophylaxis during a subsequent course of chemotherapy or conditioning treatment for SCT. Invasive aspergillosis followed by invasive candidiasis were the most frequent reasons for initiation of secondary antifungal prophylaxis. Despite the known differences in tolerability and exposure of the two drugs [26], the prophylactic efficacy of CAS and ITC was surprisingly similar in this cohort.

The clinician's choice between the two drugs was influenced by patient risk factors. Clinicians were significantly more likely to use CAS in patients with uncontrolled first IFD, uncontrolled underlying disease or those undergoing SCT.

Treatment strategies for secondary prophylaxis varied; whilst most patients started prophylaxis and chemotherapy simultaneously, treatment of the previous IFD was continued without interruption in $30.1 \%$ of the patients. This adds to the notion that subsequent chemotherapy often cannot be delayed without risking relapse or progression of underlying disease [27]. 
The $32 \%$ breakthrough rate despite secondary prophylaxis in our study was in line with the rate observed in other series $[10,11]$. Overall mortality was $16 \%$, with one-quarter of deaths being attributed to breakthrough IFD. This underlines the need for prevention. Primary antifungal prophylaxis was effective in patients undergoing remission induction chemotherapy for acute myelogenous leukaemia/myelodysplastic syndrome [28] and following allogeneic SCT [29]. In our study, better control of first IFD caused a trend towards improved outcome, a well known observation [11]. Whenever possible, IFD should be resolutely treated before exposing patients to another episode of profound long-term immunosuppression.

In our study, secondary antifungal prophylaxis with CAS or ITC was a feasible means of preventing IFD relapse. The optimal timing and antifungal drug require further exploration.

Funding: This study was supported by an unrestricted grant from MSD Sharp \& Dohme GmbH, Haar, Germany.

Competing interests: $A B$ has received research grants from Astellas Pharma, Gilead, Essex/Schering-Plough, Basilea Pharmaceutica, Pfizer and MSD (Merck) and is a consultant to/has worked at the speaker's bureau of Gilead, Essex/Schering-Plough and MSD (Merck). OAC has received research grants from Astellas Pharma, Bayer, Basilea, Genzyme Corp., Gilead, Pfizer, Merck, 
Optimer Pharmaceuticals, Schering-Plough and Vicuron Pharmaceuticals, is a consultant to Astellas Pharma, Basilea, F2G, Gilead, Pfizer, Mölnlycke, Nektar, Schering-Plough and Zeneus Pharma and worked at the speaker's bureau of Astellas Pharma, Gilead, Merck, Pfizer, Schering-Plough, SpePharm and United Medical. JM has received research grants from MSD (Merck) and is a consultant to/has worked at the speaker's bureau of MSD (Merck), Schering-Plough, Zenem, Gilead, Bio-Rad and Pfizer. GM is a consultant to Gilead, MSD (Merck), Pfizer, Essex/Schering-Plough and Novartis and has worked at the speaker's bureau of Gilead, MSD (Merck), Pfizer and Cephalon. SR has worked at the speaker's bureau of Gilead and Tibotec. MJGTR has worked at the speaker's bureau of Essex/Schering-Plough. GS has received research grants from Astellas Pharma, Cephalon, Gilead, Janssen-Cilag, MSD (Merck) and Pfizer and is a consultant to MSD (Merck). AJU is a consultant to/has worked at the speaker's bureau of Schering-Plough, Gilead, Pfizer, Astellas Pharma and MSD (Merck). JJV has worked at the speaker's bureau of MSD (Merck) and ScheringPlough and received travel grants from Gilead, MSD (Merck), Pfizer, ScheringPlough and ViroPharma. All other authors declare no competing interests.

Ethical approval: Ethical approval is not needed for a retrospective, anonymous, non-interventional case registry requesting only data collected during standard clinical practice. The study protocol was written by academic authors and approved by the Ethics Committee of Cologne University, Germany. The study 
was carried out in accordance with the Declaration of Helsinki and local ethical and legal requirements. 


\section{References}

[1] Maschmeyer G, Haas A, Cornely OA. Invasive aspergillosis: epidemiology, diagnosis and management in immunocompromised patients. Drugs 2007;67:1567-601.

[2] Maschmeyer $\mathrm{G}$. The changing epidemiology of invasive fungal infections: new threats. Int J Antimicrob Agents 2006;27(Suppl 1):3-6.

[3] McNeil MM, Nash SL, Hajjeh RA, Phelan MA, Conn LA, Plikaytis BD, et al. Trends in mortality due to invasive mycotic diseases in the United States, 1980-1997. Clin Infect Dis 2001;33:641-7.

[4] Maschmeyer G, Haas A. The epidemiology and treatment of infections in cancer patients. Int J Antimicrob Agents 2008;31:193-7.

[5] Cornely OA, Bohme A, Buchheidt D, Einsele H, Heinz WJ, Karthaus M, et al. Primary prophylaxis of invasive fungal infections in patients with hematologic malignancies. Recommendations of the Infectious Diseases Working Party of the German Society for Haematology and Oncology. Haematologica 2009;94:113-22.

[6] Maertens J, Raad I, Petrikkos G, Boogaerts M, Selleslag D, Petersen FB, et al. Efficacy and safety of caspofungin for treatment of invasive aspergillosis in patients refractory to or intolerant of conventional antifungal therapy. Clin Infect Dis 2004;39:1563-71. 
[7] Herbrecht R, Denning DW, Patterson TF, Bennett JE, Greene RE, Oestmann $\mathrm{JW}$, et al. Voriconazole versus amphotericin B for primary therapy of invasive aspergillosis. N Engl J Med 2002;347:408-15.

[8] Walsh TJ, Raad I, Patterson TF, Chandrasekar P, Donowitz GR, Graybill R, et al. Treatment of invasive aspergillosis with posaconazole in patients who are refractory to or intolerant of conventional therapy: an externally controlled trial. Clin Infect Dis 2007;44:2-12.

[9] Cornely OA, Bohme A, Reichert D, Reuter S, Maschmeyer G, Maertens J, et al. Risk factors for breakthrough invasive fungal infection during secondary prophylaxis. J Antimicrob Chemother 2008;61:939-46.

[10] Offner F, Cordonnier C, Ljungman P, Prentice HG, Engelhard D, De Bacquer D, et al. Impact of previous aspergillosis on the outcome of bone marrow transplantation. Clin Infect Dis 1998;26:1098-103.

[11] Fukuda T, Boeckh M, Guthrie KA, Mattson DK, Owens S, Wald A, et al. Invasive aspergillosis before allogeneic hematopoietic stem cell transplantation: 10-year experience at a single transplant center. Biol Blood Marrow Transplant 2004;10:494-503.

[12] Avivi I, Oren I, Haddad N, Rowe JM, Dann EJ. Stem cell transplantation post invasive fungal infection is a feasible task. Am J Hematol 2004;75:6-11.

[13] Bjerke JW, Meyers JD, Bowden RA. Hepatosplenic candidiasis-a contraindication to marrow transplantation? Blood 1994;84:2811-4. 
[14] Sipsas NV, Kontoyiannis DP. Clinical issues regarding relapsing aspergillosis and the efficacy of secondary antifungal prophylaxis in patients with hematological malignancies. Clin Infect Dis 2006;42:1584-91.

[15] Leather H, Boyette RM, Tian L, Wingard JR. Pharmacokinetic evaluation of the drug interaction between intravenous itraconazole and intravenous tacrolimus or intravenous cyclosporin A in allogeneic hematopoietic stem cell transplant recipients. Biol Blood Marrow Transplant 2006;12:325-34.

[16] Said A, Garnick JJ, Dieterle N, Peres E, Abidi MH, Ibrahim RB. Sirolimusitraconazole interaction in a hematopoietic stem cell transplant recipient. Pharmacotherapy 2006;26:289-95.

[17] Kuypers DR, Claes K, Evenepoel P, Maes B, Vandecasteele S, Vanrenterghem $\mathrm{Y}$, et al. Drug interaction between itraconazole and sirolimus in a primary renal allograft recipient. Transplantation 2005;79:737.

[18] Bermudez M, Fuster JL, Llinares E, Galera A, Gonzalez C. Itraconazolerelated increased vincristine neurotoxicity: case report and review of literature. J Pediatr Hematol Oncol 2005;27:389-92.

[19] Marr KA, Crippa F, Leisenring W, Hoyle M, Boeckh M, Balajee SA, et al. Itraconazole versus fluconazole for prevention of fungal infections in patients receiving allogeneic stem cell transplants. Blood 2004;103:1527-33.

[20] Walsh TJ, Teppler H, Donowitz GR, Maertens JA, Baden LR, Dmoszynska A, et al. Caspofungin versus liposomal amphotericin B for empirical antifungal therapy in patients with persistent fever and neutropenia. N Engl J Med $2004 ; 351: 1391-402$. 
[21] National Cancer Institute. Common toxicity criteria version 3.0.

Washington, DC: United States Department of Health and Human Services; 2003.

[22] Ascioglu S, Rex JH, de Pauw B, Bennett JE, Bille J, Crokaert F, et al. Defining opportunistic invasive fungal infections in immunocompromised patients with cancer and hematopoietic stem cell transplants: an international consensus. Clin Infect Dis 2002;34:7-14.

[23] Cornely OA, Maertens J, Bresnik M, Ebrahimi R, Ullmann AJ, Bouza E, et al. Liposomal amphotericin B as initial therapy for invasive mold infection: a randomized trial comparing a high-loading dose regimen with standard dosing (AmBiLoad trial). Clin Infect Dis 2007;44:1289-97.

[24] World Health Organization. WHO handbook for reporting results of cancer treatment. Geneva: WHO; 1979.

[25] von Elm E, Altman DG, Egger M, Pocock SJ, Gotzsche PC, Vandenbroucke JP. The Strengthening the Reporting of Observational Studies in Epidemiology (STROBE) statement: guidelines for reporting observational studies. Ann Intern Med 2007;147:573-7. Erratum. Ann Intern Med 2008;148:168.

[26] Glasmacher A, Molitor E, Hahn C, Bomba K, Ewig S, Leutner C, et al. Antifungal prophylaxis with itraconazole in neutropenic patients with acute leukaemia. Leukemia 1998;12:1338-43.

[27] Nosari A, Oreste P, Cairoli R, Montillo M, Carrafiello G, Astolfi A, et al. Invasive aspergillosis in haematological malignancies: clinical findings and 
management for intensive chemotherapy completion. Am J Hematol $2001 ; 68: 231-6$.

[28] Cornely OA, Maertens J, Winston DJ, Perfect J, Ullmann AJ, Walsh TJ, et al. Posaconazole vs. fluconazole or itraconazole prophylaxis in patients with neutropenia. N Engl J Med 2007;356:348-59.

[29] Goodman JL, Winston DJ, Greenfield RA, Chandrasekar PH, Fox B, Kaizer $\mathrm{H}$, et al. A controlled trial of fluconazole to prevent fungal infections in patients undergoing bone marrow transplantation. $\mathrm{N}$ Engl J Med 1992;326:845-51. 
Fig. 1. Primary outcome: incidence of breakthrough invasive fungal disease under secondary antifungal prophylaxis. 


\section{Table 1}

Demographic and clinical characteristics of 75 patients receiving secondary antifungal prophylaxis

\begin{tabular}{|c|c|c|c|}
\hline Characteristic & Caspofungin $(N=$ & Itraconazole $(N=$ & \\
\hline & 28) & 47) & value \\
\hline Age (years) & & & N.S. \\
\hline Median & 45 & 52 & \\
\hline Range & $16-69$ & $16-72$ & \\
\hline Female $[n(\%)]$ & $10(36 \%)$ & $18(38 \%)$ & N.S. \\
\hline Underlying malignancy & & & N.S. \\
\hline Acute lymphoblastic leukaemia & $4 \%)$ & $6(13 \%)$ & \\
\hline Acute myeloid leukaemia & $86 \%)$ & $37(79 \%)$ & \\
\hline Acute biphenotypic leukaemia & & $1(2 \%)$ & \\
\hline Lymphoma & & $3(6 \%)$ & \\
\hline Response of underlying & & & 0.028 \\
\hline malignancy at baseline & & & * \\
\hline Complete remission & $14(50.0 \%)$ & $33(70.2 \%)$ & \\
\hline Partial remission & $3(10.7 \%)$ & $9(19.1 \%)$ & \\
\hline Stable disease & $2(7.1 \%)$ & $1(2.1 \%)$ & \\
\hline Progression & $9(32.1 \%)$ & $4(8.5 \%)$ & \\
\hline Stem cell transplantation & & & 0.010 \\
\hline & & & * \\
\hline None & $14(50.0 \%)$ & $37(78.7 \%)$ & \\
\hline Allogeneic & $13(46.4 \%)$ & $7(14.9 \%)$ & \\
\hline Autologous & $1(3.6 \%)$ & $3(6.4 \%)$ & \\
\hline
\end{tabular}




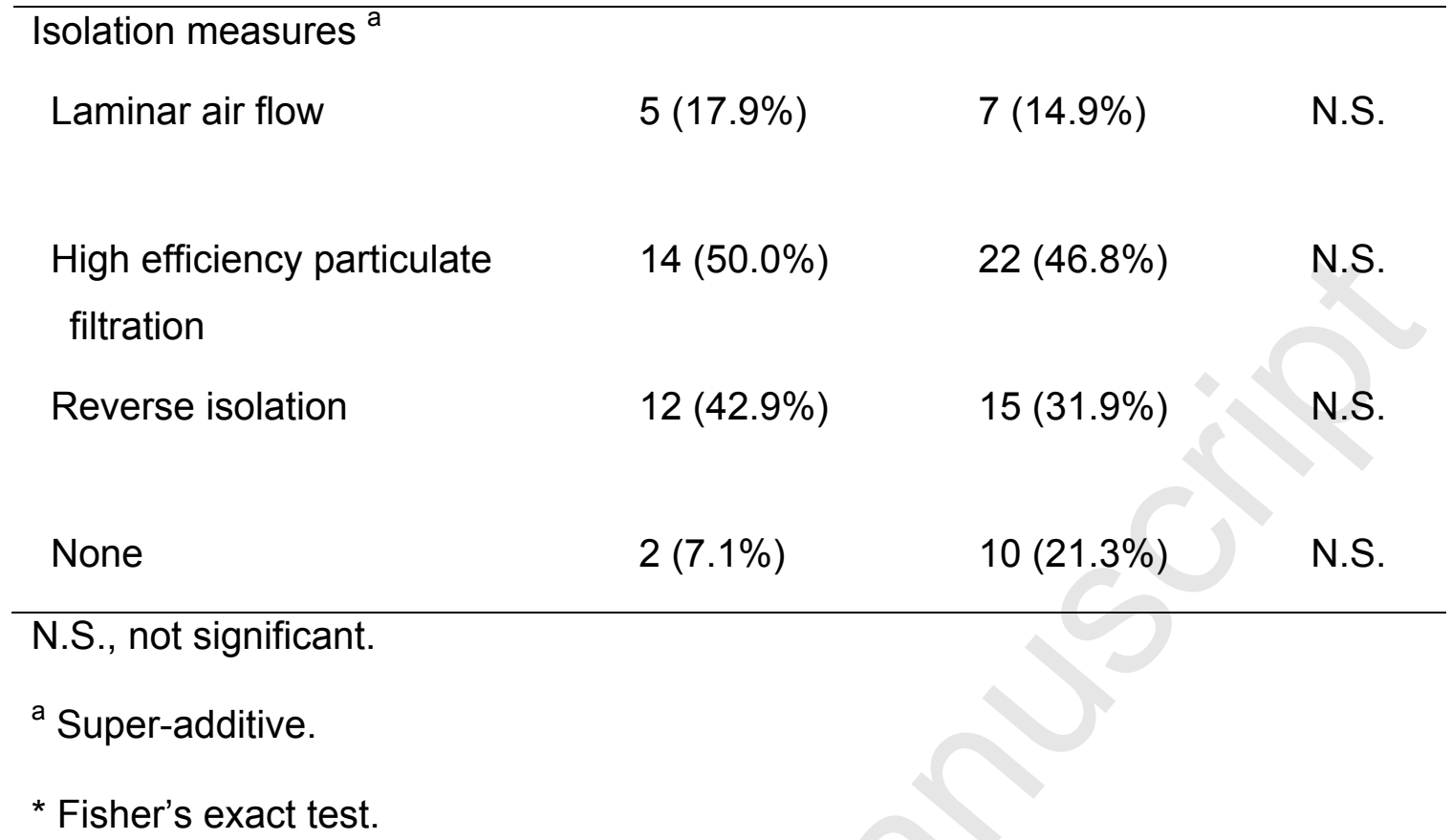




\section{Table 2}

Site, status and previous treatment of first invasive fungal disease (IFD) before initiation of secondary antifungal prophylaxis

\begin{tabular}{|c|c|c|c|}
\hline & $\begin{array}{l}\text { Caspofungin }(N \\
=28)\end{array}$ & $\begin{array}{l}\text { Itraconazole }(N \\
=47)\end{array}$ & $\begin{array}{l}P \text { - } \\
\text { value }\end{array}$ \\
\hline \multicolumn{3}{|l|}{ Evidence of first IFD } & N.S. \\
\hline Probable & $22(79 \%)$ & $38(81 \%)$ & \\
\hline Proven & $6(21 \%)$ & $9(19 \%)$ & \\
\hline Aspergillus spp. & $6(100 \%)$ & $5(56 \%)$ & N.S. \\
\hline Candida spp. & - & $2(22 \%)$ & N.S. \\
\hline Fusarium spp. & - & $1(11 \%)$ & N.S. \\
\hline Trichosporon spp. & - & $1(11 \%)$ & N.S. \\
\hline \multicolumn{4}{|l|}{ Organ involved ${ }^{a}$} \\
\hline Lung & $21(75 \%)$ & $44(94 \%)$ & N.S. \\
\hline Blood & $0(0 \%)$ & $4(9 \%)$ & N.S. \\
\hline \multirow[t]{2}{*}{ Liver } & $7(25 \%)$ & 一 & 0.001 \\
\hline & & & * \\
\hline \multirow[t]{2}{*}{ Spleen } & $4(14 \%)$ & - & 0.017 \\
\hline & & & * \\
\hline Kidney & - & - & N.S. \\
\hline Brain & - & - & N.S. \\
\hline Skin, ear, cranial bones & - & $3(6 \%)$ & N.S. \\
\hline Treatment of first IFD ${ }^{a}$ & & & N.S. \\
\hline AMB lipid complex & $2(7 \%)$ & - & \\
\hline AMB deoxycholate & $13(46 \%)$ & $23(49 \%)$ & \\
\hline
\end{tabular}




\begin{tabular}{lll}
\hline Liposomal AMB & $9(32 \%)$ & $19(40 \%)$ \\
Caspofungin & $17(61 \%)$ & $9(19 \%)$ \\
Fluconazole & $4(14 \%)$ & $5(11 \%)$ \\
Itraconazole & $11(39 \%)$ & $24(51 \%)$ \\
Voriconazole & $8(29 \%)$ & $8(17 \%)$ \\
5-Flucytosine & - & $2(4 \%)$ \\
Response of first IFD & & \\
& & $20(42.6 \%)$ \\
Complete response & $17(60.7 \%)$ & $25(53.2 \%)$ \\
Partial response & $4(14.3 \%)$ & $2(4.3 \%)$ \\
Stable disease & $3(10.7 \%)$ & - \\
Progression & $15(54 \%)$ & $24(51 \%)$ \\
Chemotherapy delayed due to & & \\
treatment of first IFD & & \\
\hline N.S., not significant; AMB, amphotericin B. & \\
a Super-additive. & & \\
Fisher's exact test. & & \\
\hline
\end{tabular}




\section{Table 3}

Incidence, site and outcome of breakthrough invasive fungal disease (IFD) with secondary antifungal prophylaxis

\begin{tabular}{|c|c|c|c|}
\hline & $\begin{array}{l}\text { Caspofungin }(N= \\
28)\end{array}$ & $\begin{array}{l}\text { Itraconazole }(N= \\
47)\end{array}$ & $\begin{array}{l}P \text { - } \\
\text { value }\end{array}$ \\
\hline Breakthrough IFD & & & N.S. \\
\hline Proven & $1(3.6 \%)$ & $2(4.3 \%)$ & \\
\hline Probable & $7(25.0 \%)$ & $6(12.8 \%)$ & \\
\hline Possible & $1(3.6 \%)$ & $7(14.9 \%)$ & \\
\hline $\begin{array}{l}\text { Outcome of breakthrough } \\
\text { IFD }\end{array}$ & & & N.S. \\
\hline Complete response & $1(11.1 \%)$ & $4(26.7 \%)$ & \\
\hline Partial response & $2(22.2 \%)$ & $6(40.0 \%)$ & \\
\hline Stable disease & $4(44.4 \%)$ & $1(6.7 \%)$ & \\
\hline Progression & $2(22.2 \%)$ & $3(20.0 \%)$ & \\
\hline Unknown & & $1(6.7 \%)$ & \\
\hline Site of breakthrough IFD ${ }^{a}$ & & & \\
\hline Lung & $7(77.8 \%)$ & $14(93.3 \%)$ & N.S. \\
\hline Blood & - & $1(6.7 \%)$ & N.S. \\
\hline Liver & $3(33.3 \%)$ & $2(13.3 \%)$ & N.S. \\
\hline Spleen & $2(22.2 \%)$ & $2(13.3 \%)$ & N.S. \\
\hline Brain & $1(11.1 \%)$ & $1(6.7 \%)$ & N.S. \\
\hline Overall mortality & $7(25.0 \%)$ & $5(10.6 \%)$ & N.S. \\
\hline Mortality attributable to IFD & $1(3.6 \%)$ & $2(4.3 \%)$ & N.S. \\
\hline
\end{tabular}


a Super-additive. 


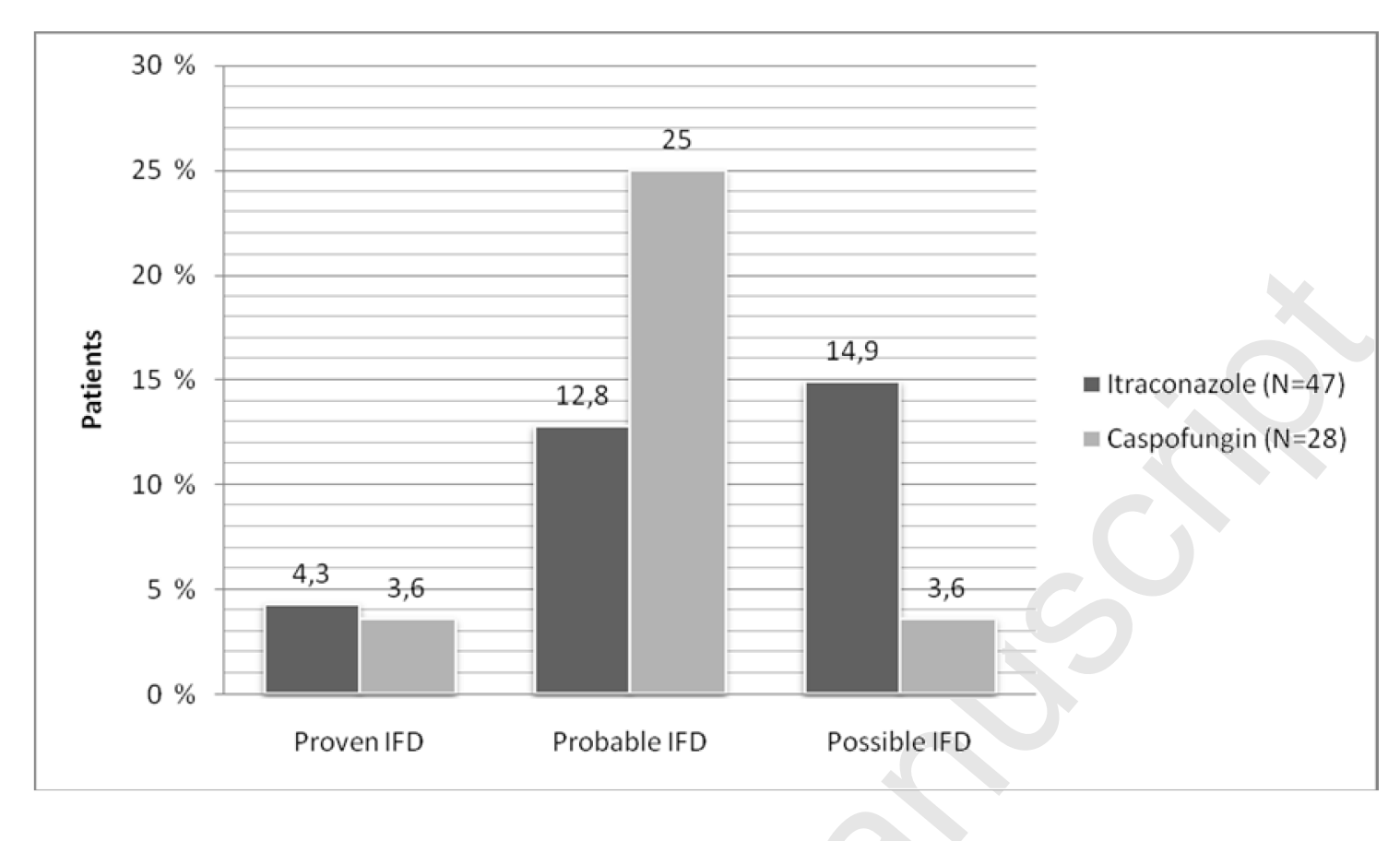

.

(1)
(1) 